ORIGINAL ARTICLE

\title{
Compliance with external hip protectors in nursing homes in Norway
}

\author{
L Forsén, S Sandvig, A Schuller, A J Søgaard
}

Injury Prevention 2004;10:344-349. doi: 10.1136/ip.2004.005124

See end of article for authors' affiliations auther affiliations

Correspondence to: Dr Lisa Forsén, Division of Epidemiology, Norwegian Institute of Public Health, Post Box 4404 Nydalen, Oslo, Norway; lisa. forsen@fhi.no

\begin{abstract}
Objectives: To investigate compliance with hip protector use.
Design: Observational prospective study.

Setting: 19 nursing homes (1040 beds).

Subjects: All residents during an 18 month period were included in this study.

Intervention: Hip protectors were introduced as a regular part of health care service for all residents. Residents at high risk were encouraged to use hip protectors regularly. Each nursing home had a contact person.

Main outcome measures: The percentage of residents accepting the hip protector offer, probability of continued use, reasons for terminating use, and percentage of falls with hip protector were evaluated. Results: Fifty five percent of the residents accepted the hip protector offer. The percentage increased by age, but showed no significant dependence on gender, profession of the contact person, or size of nursing home. The probability of continued use showed no significant dependence on age and gender. Nursing homes with a nurse as contact person showed $51 \%$ higher risk of residents terminating regular hip protector use than nursing homes with a physiotherapist as contact person (relative risk (RR) 1.51, 95\% confidence interval $(\mathrm{Cl}) 1.11$ to $2.05, \mathrm{p}=0.008)$. The corresponding result for large $(75-92$ beds) compared with small (24-68 beds) nursing homes was $R R=1.44$ (95\% Cl 1.02 to 2.02, $p=0.036$ ). Seventy six percent of 2323 falls occurred while using hip protectors.

Conclusion: The contact person and size of the nursing home seemed to be important factors for continued use of hip protectors while age and gender seemed to be less important.
\end{abstract}

$\mathrm{N}$ orway has one of the highest incidences of hip fracture in the world ${ }^{12}$ and the incidence has increased during the past decades. ${ }^{3}{ }^{4}$ A recent study shows that while the incidence of hip fracture in Oslo has not changed significantly during the last decade, it is still the highest reported incidence in the world. ${ }^{5}$ The cold Oslo climate does not seem to contribute to the high incidence. ${ }^{5}$ Several prognoses estimate that because of an increase in the number of elderly people, the number of hip fractures will increase significantly world wide during the next 25 years if preventive measures are not improved.$^{6-8}$

In 1993 and 1997 use of the SAFEHIP hip protector in high risk groups showed a significant reduction in the number of hip fractures. ${ }^{9-11}$ The Norwegian health authorities wanted therefore to investigate the effect of this hip protector in preventing hip fractures in a "real world" setting. The hip protector was implemented in 1998-99 free of charge in 19 nursing homes as a regular part of the daily health care for all consenting residents.

The present paper is the third in a series addressing this hip protector intervention. The first paper showed a 39\% reduction of the incidence of hip fracture in the participating nursing homes during the intervention period compared with an 18 month pre-intervention period. ${ }^{12}$ The second paper concluded that persons at high risk of hip fracture in nursing homes may decrease the risk to one third by wearing a hip protector in a fall. ${ }^{13}$

Many studies have shown that the percentages of acceptance and daily use of hip protectors are often low because many elderly people find the protector uncomfortable when resting and cumbersome when dressing and undressing. ${ }^{11}{ }^{14}{ }^{15}$ These studies were randomised controlled trials that investigated the effect of hip protectors to prevent hip fractures in nursing homes. Two of the articles in a systematic review ${ }^{15}$ describe relatively large, randomised interventions in nursing homes and rest homes (intervention group $\leqslant 384$ ) studying long term (4-10 months) compliance with hip protectors to prevent hip fracture. ${ }^{16}{ }^{17}$ The other articles included in the systematic review ${ }^{15}$ described smaller studies $(\mathrm{n}=10-29)$.

The aim of the present paper was to examine the percentages of acceptance and long term use of hip protectors when offered free of charge to all residents in nursing homes ( 1040 beds) as a regular part of the daily health care that the residents receive from the nursing staff. Random selection of residents was not allowed. The Norwegian health authorities wanted a fair, "real world" setting. The aims of this study were to analyse acceptance of being a regular user of hip protectors, to estimate the probability of continued use during a 12 month period, to study the main reasons for stopping regular use, and to report the percentage of falls with hip protectors.

\section{METHOD}

\section{Intervention}

Over a period of 18 months every resident in all 19 nursing homes (a total of 1040 beds) was enrolled in the study. Approximately half of the residents had signs of dementia, but no resident was excluded.

The families of the residents received a letter from the municipality medical officer explaining the use of hip protectors, the potential risks and benefits, and the objectives of the study. In January 1998 the project manager gave the employees in the nursing homes a one hour presentation including fracture and fall prevention in general and the use of hip protectors. The manager then visited each nursing home and gave one to four hours of additional instruction on 
how to implement hip protectors. ${ }^{12}$ By 1 May 1998 all 19 nursing homes were involved in the project.

During the intervention period the project manager provided ongoing motivational activities to the nursing homes aimed at encouraging and supporting participation. The project manager had a contact person, a physiotherapist or nurse, among the employees in each nursing home. Contact persons were responsible for the hip protectors in their nursing home, registration of hip protector use (completing a user questionnaire) and falls (completing a fall questionnaire), and for secure storage of the questionnaires. The project manager brought the hip protectors to the nursing homes and the contact persons distributed them to the residents. The health authorities covered the costs.

Residents with the diagnosis "osteoporosis", or who had fallen, complained of dizziness, were cognitively impaired, had earlier fractures, and/or had low body mass index were considered to be at high risk of hip fracture. The contact persons were instructed that every resident should be offered hip protectors but those who were considered high risk should be especially encouraged to become a regular user. A regular user of hip protectors was defined as a resident with hip protector use as a part of the daily health care he/she received from the staff. Every day the regular users received a reminder to wear the hip protector. Members of staff were especially aware of the cognitively impaired because of their high risk of hip fracture due to their inability to be careful.

Each occurrence of hip fracture (that is, fractura colli femoris and fractura pertrochanterica) was registered during the 18 months of intervention. ${ }^{12}$ The registration was compared with the information registered in the corresponding patient's notes at Bærum hospital where all patients with hip fracture were sent. If the information registered in the home and that in the notes did not agree, the registration was corrected in accordance with the patient's notes. For quality assurance, the operation protocol was also studied.

The Data Inspectorate of Norway, the Norwegian Board of Health, and the Regional Committee for Medical Research Ethics approved the study.

\section{Compliance study questionnaire}

The employees completed a one page questionnaire concerning use/non-use of the hip protector. The registration lasted for up to 12 months within the 18 months of intervention. This questionnaire was completed for each resident at the start of the intervention at her/his respective nursing home and also later for each new resident who moved into the home. When a resident died or for other reasons left the nursing home, the bed was immediately occupied by a new person who received the same hip protector offer. Persons who were not willing to use the hip protector were defined as non-users. However, some of the residents changed their mind after a while (for example, after a fall) and were registered as users from that day, as is natural in a "real world" setting. The observation time started from the first day as regular user as for all the other users. Their non-user status was corrected to user status in the user questionnaire. The time and reasons for termination were registered for those who stopped using the hip protector. Among users the time of day during which the hip protector was used (day, evening, and/or night-time) was registered. After the first day of registration, the same registration was repeated each day the next week. Thereafter the registration was repeated monthly during the next 11 months. Registration was continued for 12 months for each user of hip protectors during the total study period of 18 months. Residents who died or moved within 12 months or individuals who became regular users during the last year of intervention did not achieve a full year of registration.
During the entire intervention period, the employees at 15 of the 19 nursing homes (790 beds) completed a questionnaire each time a fall had occurred among the residents and judged whether the hip protector, if worn, was correctly in place at the time of the fall. The questionnaire also contained a question about whether the resident was a regular user of hip protectors. A fall was defined as the resident having unintentionally landed on the floor or the ground.

\section{Definition of compliance}

One theoretical definition of compliance is "the extent to which a person's behaviour coincides with medical or health advice" ${ }^{\prime 18}$ We measured the degree of compliance in four different ways that all express the extent to which the residents' behaviour coincided with the advice of using hip protectors:

(1) The percentage who accepted the hip protector offer.

(2) The percentage who continued use.

(3) The percentage of regular users at given points of time.

(4) The percentage of falls protected with the hip protector.

\section{Statistical methods}

Logistic regression was used to study the acceptance/nonacceptance of the hip protector offer (compliance measure 1) controlled for age, gender, profession of the contact person, and the size of the nursing home.

Kaplan-Meier curves were used to compare the probability that the residents continued being a daytime user of the hip protector (compliance measure 2). By means of Cox regression the comparison was adjusted for age and gender, profession of the contact person, and the size of the nursing home. We analysed the daytime hip protector use (day and afternoon together because they did not differ) and computed the percentage of night use among the daytime users.

\section{RESULTS}

\section{Acceptance of the hip protector offer}

Fifty five percent of the residents registered in the user/nonuser file had accepted the offer of hip protectors. The tendency of accepting was higher among women (57\%) than among men $(50 \%), p=0.028$ (table 1 ). Since women had a

\begin{tabular}{|c|c|c|c|}
\hline & No $(\%)$ women & No (\%) men & No $(\%)$ total \\
\hline $\begin{array}{l}\text { User of the hip } \\
\text { protector }\end{array}$ & $443(57)$ & $175(50)$ & $618(55)$ \\
\hline$\%$ of users & 72 & 28 & 100 \\
\hline $\begin{array}{l}\text { Mean (SD) age in } \\
\text { years }\end{array}$ & $84(8)$ & $80(7)$ & $83(8)$ \\
\hline Age range & 54-104 & $56-99$ & $54-104$ \\
\hline $\begin{array}{l}\text { Non-user of the hip } \\
\text { protector }\end{array}$ & 336 (43) & $176(50)$ & $512(45)$ \\
\hline$\%$ of non-users & 66 & 34 & 100 \\
\hline $\begin{array}{l}\text { Mean (SD) age in } \\
\text { years }\end{array}$ & $82(10)$ & $79(10)$ & $81(10)$ \\
\hline Age range & 38-104 & $35-99$ & $35-104$ \\
\hline Total & $(100)$ & $351(100)$ & $1130(100)$ \\
\hline$\%$ of all & 69 & 31 & 100 \\
\hline $\begin{array}{l}\text { Mean (SD) age in } \\
\text { years }\end{array}$ & $83(9)$ & 79 (9) & $82(9)$ \\
\hline Age range & 38-104 & $35-99$ & $35-104$ \\
\hline
\end{tabular}


Table 2 Factors that were important for the probability of accepting the offer of hip protectors analysed by multiple logistic regression (dependent variable: accepted the offer $=1$, not accepted $=0$ )

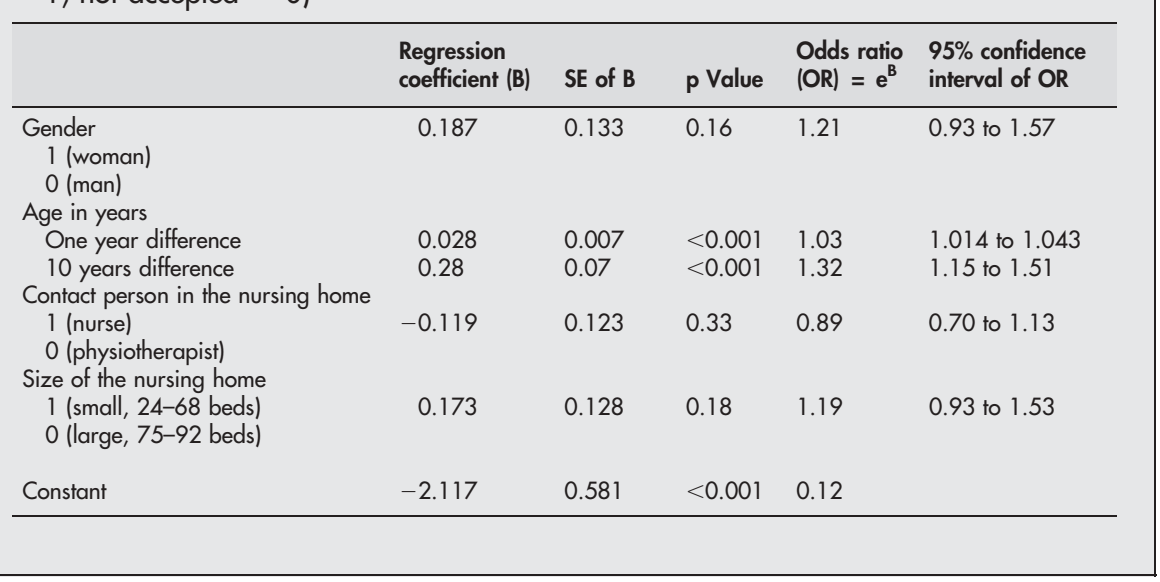

higher mean age, 84 years compared with 80 years in men, gender was not significant for accepting the offer $(p=0.16)$ when controlling for age (table 2). The contact person in the nursing home and the size of the nursing home were also not significant (table 2). Age was the only significant covariate in the analysis of the probability of accepting the offer of hip protectors $(p<0.001)$. For an age difference of 10 years the odds ratio of accepting was $1.32(\mathrm{p}<0.001)$.

The main reasons for not accepting the offer of hip protectors were "strongly in need of care-that is, the bedridden" (30\% of the 512 non-users), and "did not want to use it" (25\% of the 512 non-users). Five percent stated difficulties with clothing and $12 \%$ stated distaste and unwanted side effects. Four percent had missing information and the rest were not eligible (near death, planned move to

Table 3 Hip protector user status by the end of the registration period for the individual resident

\begin{tabular}{llll}
\hline User status & $\begin{array}{l}\text { No (\%) } \\
\text { women }\end{array}$ & $\begin{array}{l}\text { No (\%) } \\
\text { men }\end{array}$ & $\begin{array}{l}\text { No (\%) } \\
\text { total }\end{array}$ \\
\hline $\begin{array}{l}\text { Continued user of the hip } \\
\text { protector at the end of the } \\
\text { intervention* }\end{array}$ & $194(44)$ & $71(41)$ & $265(43)$ \\
$\begin{array}{l}\text { Terminated use of hip } \\
\text { protector in or before the } \\
12 \text { th month because of } \\
\text { unwanted side effects, distaste, } \\
\text { difficulties with clothing, or } \\
\text { simply "will not" }\end{array}$ & $125(28)$ & $47(27)$ & $172(28)$ \\
$\begin{array}{l}\text { Deceased before the 12th } \\
\text { montht }\end{array}$ & $53(12)$ & $27(15)$ & $80(13)$ \\
$\begin{array}{l}\text { Moved before the 12th } \\
\text { month† }\end{array}$ & $34(8)$ & $14(8)$ & $48(8)$ \\
$\begin{array}{l}\text { Not of current interest } \\
\text { because of lower level of } \\
\text { functioning as in great } \\
\text { need of care }\end{array}$ & $37(8)$ & $16(9)$ & $53(9)$ \\
$\begin{array}{l}\text { The total number of } \\
\text { residents that had accepted } \\
\text { the offer of hip protectors }\end{array}$ & $443(100)$ & $175(100)$ & $618(100)$ \\
\hline
\end{tabular}

* Of 268 users 90 could not be registered for 12 months because they became users when the intervention period had less than 12 months remaining. They were therefore censored.

tCensored in the Kaplan-Meier method and in the Cox regression method (see fig 1 and table 4). another facility, or no need for hip protectors for other reasons).

\section{Reasons for terminating use of hip protectors}

For both men and women approximately $28 \%$ of the residents who accepted the offer of hip protectors stopped being regular users within the registration period of up to 12 months (table 3). They stopped because of unwanted side effects, distaste, difficulties with clothing, or simply because they did not want to continue. Soreness, pain in the thigh, heat rash, and redness were examples of unwanted side effects. Other reasons for terminating hip protector use were, for example, that the resident had bedsores or that the hip protector was too small or too tight.

Of the original 618 users a number of residents who "stopped" using hip protectors had died (13\%), moved (8\%) or were for other reasons no longer in need of hip protectors $(9 \%)$, for example those who were bedridden after stroke (table 3).

\section{Users of hip protectors}

At the end of the registration period of up to 12 months, $43 \%$ of the original 618 users were still using the hip protector (table 3 ). The percentage of users among women was somewhat higher than among men (44\% v 41\%).

Among the total number of residents registered on the user/non-user forms, 265 of 1131 (23\%) were users at the end of the registration period. At least $61 \%(265 /(265+172))$ of the original 618 users who were still eligible as users at the end of the intervention were still using hip protectors (table 3).

Nursing homes with a nurse as contact person showed a smaller probability of continued use (compliance measure 2) than homes with a physiotherapist as contact person (fig l). The risk of a resident stopping regular use here was 51\% higher than the corresponding risk at a nursing home with a physiotherapist as contact person $(\mathrm{p}=0.008$, table 4$)$.

Large nursing homes showed a greater probability of continued use than small homes (fig 2). The contact person was a physiotherapist in $63 \%$ of the large nursing homes and in $49 \%$ of the small homes (data not shown). However, there was still an effect of the size of the nursing home when controlling for the profession of the contact person (table 4), while age and gender had no significant effect on the probability of continued use of the hip protector.

The percentage of regular hip protector users on a given day in the nursing homes (compliance measure 3) in May 1998 was $35 \%$ (95\% confidence interval (CI) $32 \%$ to $38 \%$ ) and 


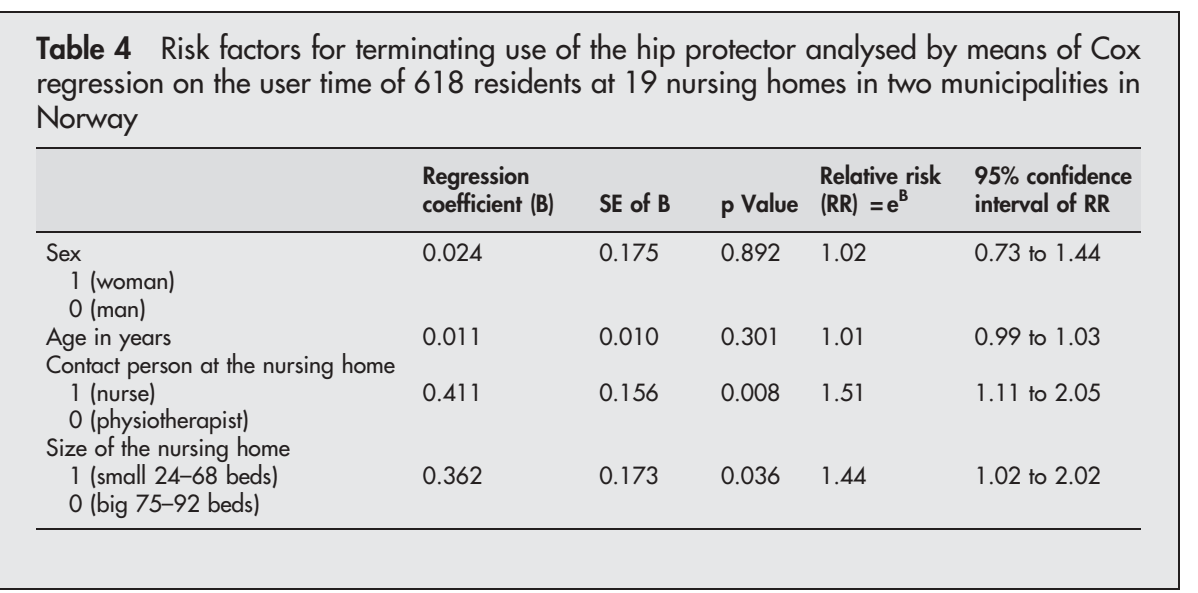

$22 \%(95 \%$ CI $20 \%$ to $25 \%$ ) in November 1999 (data not shown).

The percentage night use of hip protectors among the daytime users varied between $40 \%$ and $45 \%$ the first months of the registration period of 12 months and between $36 \%$ and $39 \%$ the last months of the registration period (data not shown).

\section{Percentage protected falls}

Seventy percent of the registered users wore a hip protector in their first fall, and $76 \%$ of all registered falls among the regular users $(n=2323)$ occurred with a hip protector on (data not shown). The proportion of protected falls among the users in the second third and fourth fall was $74 \%, 73 \%$ and $72 \%$, respectively (data not shown).

\section{DISCUSSION}

\section{Main findings}

This large intervention in a "real world" setting in nursing homes in Norway revealed that about half of the residents accepted the offer of hip protectors. However, for both men and women approximately $28 \%$ terminated hip protector use within 12 months because of unwanted side effects, distaste, difficulties with clothing, or simply did not continue. The probability of still being a regular hip protector user at the end of the registration period of up to 12 months (given that

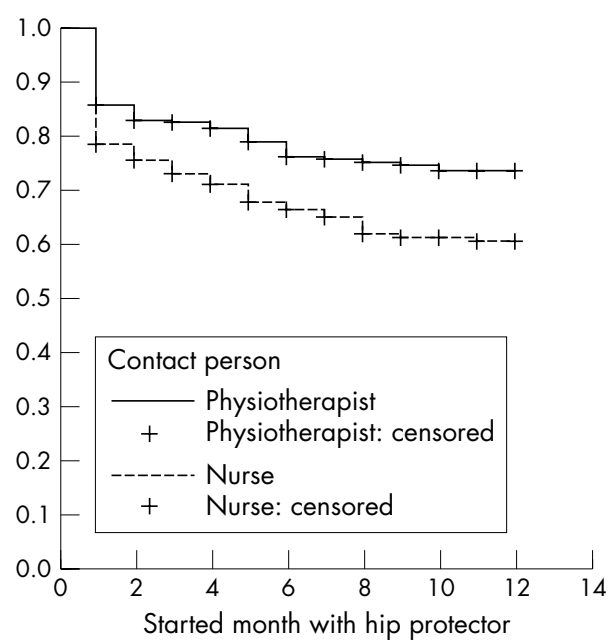

Figure 1 Probability of still using the hip protector at each commenced month as user within nursing homes with physiotherapist as contact person (eight nursing homes) and within nursing homes with nurse as contact person (11 nursing homes); log rank statistic $=9.96, p=0.002$ (Kaplan-Meier). the resident was still eligible for use) was higher in nursing homes where a physiotherapist was contact person than where a nurse was the contact person. The fact that the project manager was a physiotherapist may have had an influence on the contact person's attitude to hip protector use. The probability of still being a user of hip protectors was higher in large compared with small nursing homes. The large homes had presumably a larger probability of finding a contact person who believed in the hip protector because they had more employees to choose among. It is also possible that employees at large nursing homes had better possibilities for further education.

The compliance in our study seemed to decrease during the intervention (compliance measure 3), while number of users among the total number of fallers increased..$^{13}$ One explanation for these apparently conflicting results may be that the ability of employees to concentrate on residents at highest risk probably improved during the intervention as the overall percentage of users decreased.

For some of the employees the work in convincing residents about the positive effect of hip protector use was more difficult after each time a hip fracture occurred while using a hip protector. During the intervention there were 12 such occurrences. ${ }^{12}$ Despite the benefits of hip protector use, employees should be aware of the fact that a hip protector cannot prevent hip fracture in all circumstances. ${ }^{13}$

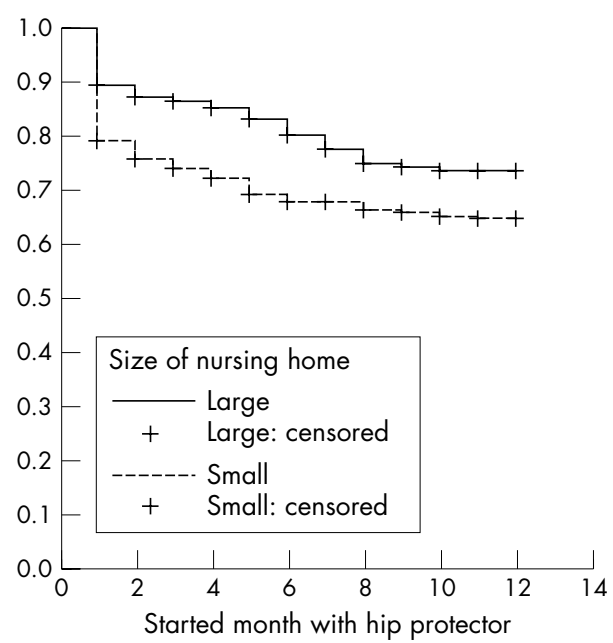

Figure 2 Probability of still using the hip protector at each commenced month as user within small nursing homes (24-68 beds, concerning 14 nursing homes) and within large nursing homes (75-92 beds, concerning five nursing homes); log rank statistic $=7.37, p=0.007$ (Kaplan-Meier). 


\section{Key points}

- Half of all the residents in the nursing homes accepted the offer of hip protectors free of charge as a regular part of the daily health care that they received at their nursing home.

- For both men and women about $28 \%$ terminated the use of hip protectors within 12 months because of unwanted side effects, distaste, difficulties with clothing, or simply because they did not want to continue.

- Nursing homes with a nurse as contact person in the hip protector study showed a $51 \%$ higher risk of residents terminating their use of hip protectors than homes with a physiotherapist as contact person.

- Seventy six percent of the 2323 registered falls during 18 months occurred while the hip protector was being used.

\section{Comparison with other studies}

It is difficult to compare compliance with hip protector use across studies. ${ }^{15}$ There is no generally accepted definition and methods of assessment differ. One relatively valid method may be to compare the proportion of protected falls, but a premise is that the falls are defined and registered in the same careful way and that the denominators are comparable. In the study by Meyer et al, 54\% of the falls were protected among the intervention group (adjusted for cluster randomisation), ${ }^{19}$ while the corresponding number in our study was only $44 \%$ of 2323 falls (data not shown). A problem with this comparison is that our intervention group included all residents at the nursing homes but Meyer's intervention excluded the bedridden. ${ }^{19}$ A better comparison may be to compare only those who accepted the hip protector offer. In a study by Kannus et al, $74 \%$ of all the falls in the intervention group occurred while using a hip protector. ${ }^{8}$ Their intervention group included only those who agreed to wear the protector. In our study $70 \%$ of the registered users wore a hip protector in their first fall, and $76 \%$ of all falls among the users occurred with the hip protector on. The proportion of regular users among all fallers increased during our intervention, ${ }^{13}$ whereas the proportion of protected falls among the users varied between $70 \%$ and $74 \%$ in the first, second, third, and fourth fall. Measured in this way (compliance measure 4), compliance in our intervention and the intervention described by Kannus et al were similar assuming that our regular users and their intervention group were comparable. Making this assumption, it seems that compliance (compliance measure 4) in our intervention that was designed to represent a "real world" setting was as good as in the randomised controlled trial of Kannus et al. ${ }^{8}$

Our finding that compliance differed according to variables at nursing home level (size and contact person) supports the impression from other studies. The attitude of the staff in institutions is a crucial factor for getting good compliance. $^{14}{ }^{19-21}$

The reasons for stopping use of hip protectors reported in our study support the findings of Yasumura et al. ${ }^{22}$ The reasons for drop out were difficulty in wearing the hip protector and delay in using the toilet.

\section{Limitations and strengths}

There were probably some missing residents in the register of non-users, resulting in an overestimation of the percentage accepting the offer of hip protectors. Some dying residents were probably not registered and some of the individuals who were staying only a short time were probably also not registered. However, the percentage of users near the end of the intervention period (November 1999) gave nearly the same result as the percentage at the end of the registration period for the respective users measured in the user/non-user data. This indicates that there were probably not many missing non-users in the user/non-user data. The percentage of regular users on one day in November 1999 was 22, while the percentage of users in the user/non-user data was 23 $(265 / 1131)$ at the end of the registration.

The adjustment for confounders, both in the residents and in the nursing homes, was limited. In addition, we did not have an objective checklist for choosing residents who should be especially encouraged to be regular users of the hip protector.

The strength of our intervention was that it was large with many beds (1040) and prospective for 18 months. In addition it gives new evidence to all the randomised controlled trials because our study was in a "real life" situation with:

(1) No randomisation.

(2) Everybody received the offer to use the hip protector irrespective of their risk status for hip fracture.

(3) Those at the highest risk of hip fracture were especially encouraged to be regular users of the hip protector.

(4) Those who did not accept the offer at once had the opportunity to change their mind.

(5) New residents moving into the nursing home received the same offer.

\section{Conclusion and further research}

The compliance achieved in this hip protector intervention in nursing homes in Asker and Bærum was comparable with compliance in randomised controlled trials. The contact persons and the size of the nursing homes seemed to be important for continued use of hip protectors, but the age and gender of users seemed to be of less importance.

There are a number of challenges that warrant further investigation. Firstly, optimal teaching programs for the employees need to be further developed ${ }^{19}$ such that attitudes toward protectors are improved. Secondly, an objective checklist to identify individuals at high risk of hip fracture in the non-user group is needed in order to encourage these individuals to become users. Thirdly, new hip protectors should be made more comfortable without reducing the preventive effect so that the compliance in the user group will increase. Fourthly, a solution needs to be found for hip protector users who lose their balance while dressing or undressing.

\section{ACKNOWLEDGEMENTS}

We want to thank Asker and Bærum municipality, Akershus County Administration, and Bærum Hospital for financing the project. We also want to thank the employees and the residents at the participating nursing homes. The authors have no conflict of interest or competing interest with respect to the hip protector included in this study.

\section{Authors' affiliations \\ L Forsén, A J Søgaard, Norwegian Institute of Public Health, Oslo, Norway \\ S Sandvig, Norwegian Cancer Society, Oslo, Norway \\ A Schuller, TNO Prevention and Health, Leiden, The Netherlands}

\section{REFERENCES}

1 Johnell O, Gullberg B, Allander E, et al. The apparent incidence of hip fracture in Europe: a study of national register sources. MEDOS Study Group. Osteoporos Int 1992;2:298-302. 
2 Meyer HE, Falch JA, $\mathrm{O}^{\prime}$ Neill T, et al. Height and body mass index in Oslo, Norway, compared to other regions of Europe: do they explain differences in the incidence of hip fracture? European Vertebral Osteoporosis Study Group. Bone 1995; 17:347-50.

3 Falch JA, Kaastad TS, Bohler G, et al. Secular increase and geographical differences in hip fracture incidence in Norway. Bone 1993; 14:643-5.

4 Finsen V, Benum P. Changing incidence of hip fractures in rural and urban areas of central Norway. Clin Orthop 1987:104-10.

5 Lofthus CM, Osnes EK, Falch J, et al. Epidemiology of hip fractures in Oslo, Norway. Bone 2001;29:413-8.

6 Gullberg B, Johnell O, Kanis JA. World-wide projections for hip fracture. Osteoporos Int 1997;7:407-13

7 Kanis JA. The incidence of hip fracture in Europe. Osteoporos Int 1993:3(suppl 1):10-15.

8 Kannus P, Niemi S, Parkkari J, et al. Hip fractures in Finland between 1970 and 1997 and predictions for the future [see comments]. Lancet 1999;353:802-5

9 Ekman A, Mallmin H, Michaelsson K, et al. External hip protectors to prevent osteoporotic hip fractures [letter; comment]. Lancet 1997;350:563-4.

10 Lauritzen JB, Petersen MM, Lund B. Effect of external hip protectors on hip fractures [see comments]. Lancet 1993;341:11-3.

11 Parker MJ, Gillespie LD, Gillespie WJ. Hip protectors for preventing hip fractures in the elderly (Cochrane review). Cochrane Database Syst Rev 2002:CD001255.

12 Forsén L, Arstad C, Sandvig S, et al. Prevention of hip fracture by external hip protectors. An intervention in 17 nursing homes in two municipalities in Norway. Scandinavian Journal of Public Health 2003;31:261-6.
13 Forsén L, Søgaard A, Sandvig S, et al. Risk of hip fracture in protected and unprotected falls in nursing homes in Norway. Inj Prev 2004; 10:16-20.

14 Cryer C, Knox A, Martin D, Barlow J, Cantebury hip protector project team. Hip protector compliance among older people living in residential care homes. Inj Prev 2002;8:202-6.

15 van Schoor NM, Deville WL, Bouter LM, et al. Acceptance and compliance with external hip protectors: a systematic review of the literature. Osteoporosis Int 2002;13:917-24.

16 Hubacher M, Wettstein A. Acceptance of hip protectors for hip fracture prevention in nursing homes. Osteoporos Int 2001;12:794-9.

17 Villar T, Hill P, Inskip H, et al. Will elderly rest home residents wear hip protectors? Age Ageing 1998;27:195-8.

18 Haynes RB, Taylor DW, Sackett DL. Compliance in health care. Baltimore, MD: Johns Hopkins University Press, 1979.

19 Meyer G, Warnke A, Bender R, et al. Effect on hip fractures of increased use of hip protectors in nursing homes: cluster randomised controlled trial [comment]. BMJ 2003;326:76.

20 Parkkari J, Heikkilä J, Kannus P. Acceptability and compliance with wearing energy-shunting hip protectors. Age Ageing 1998;27:225-9.

21 Ross JE, Woodworth GW, Wallace RB. Compliance by elderly in wearing hip joint protectors. Proceedings of the Third International Conference on Injury Prevention and Control. Melbourne, Australia, 1996 (abstract 298).

22 Yasumura S, Suzuki T, Yoshida H, et al. [Compliance concerning external protectors for hip fractures among the institutionalized elderly in Japan]. Nippon Ronen lgakkai Zasshi 1999;36:268-73.

\section{BOARD MEMBER BIOGRAPHY}

\section{Andrés Villaveces}

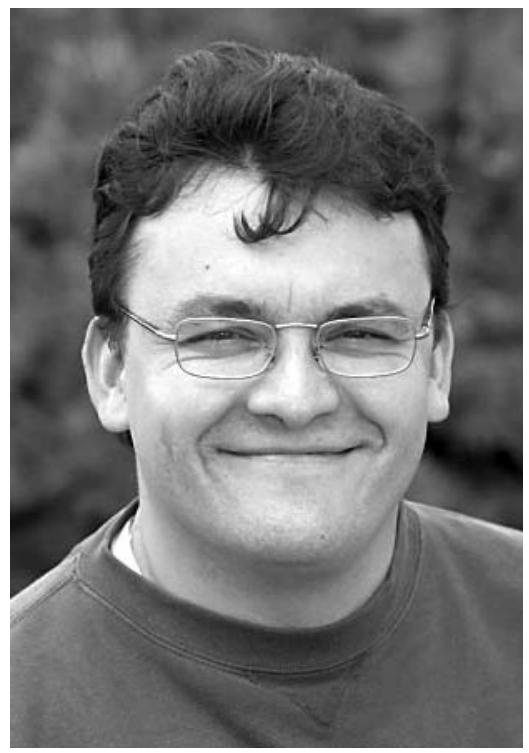

D Andrés Villaveces is a research associate at the Cisalva Institute, University of El Valle, Cali, Colombia where he participates in studies on firearm injury risk factors. He earned a medical degree at the Escuela Colombiana de Medicina in Bogotá, Colombia. He completed a masters degree in public health at the Rollins School of Public Health of Emory University, Atlanta, Georgia with a scholarship from the Japan-Inter-American Development Bank Scholarship Program. His work in public health in Colombia led him to the field of injury prevention, specifically to the prevention of homicides due to firearms. He completed doctoral studies in epidemiology at the University of Washington School of Public Health and Community Medicine in Seattle, Washington. His dissertation focused on the effects of alcohol related laws on mortality due to traffic injuries. As a research associate of the Harborview Injury Prevention and Research Center at the University of Washington, he collaborated on studies of alcohol consumption and traffic injuries and firearm safety storage devices and suicide.

Andrés worked as a medical officer at the Department of Injuries and Violence Prevention at the WHO in Geneva, Switzerland. There, with input from researchers from academic institutions around the world, he developed the TEACH-VIP injury prevention curriculum and coauthored WHO policy documents on violence prevention.

Andrés worked on a road traffic safety project in Uganda as a consultant for the Transport Research Laboratory and the Leeds School of Medicine, UK. He has also consulted on injury prevention projects for the Small Arms Survey of the University of Geneva and the Centre for Humanitarian Action, both in Geneva, Switzerland, the European Office of the WHO, Rome, Italy, and the Pan-American Health Organization, Washington, DC.

In addition he has participated in injury prevention training courses in Colombia, Mexico, Vietnam, and Uganda. Andrés is interested in developing injury prevention training activities and research in low and middle income countries as well as using epidemiologic methods to help understand local problems. 